\title{
ENHANCING CONCEPT COMPREHENSION AND RECALL THROUGH IMAGERY: THE CASE FOR INTERNATIONAL STUDENTS ${ }^{*}$
}

\author{
C. Jane Edwards \\ Eynesbury Institute of Business and Technology \\ University of South Australia, Adelaide, Australia
}

\begin{abstract}
Teaching new marketing concepts to international students (from non-native speaking backgrounds) often poses challenges for lecturers. Past assessment results show that brand development strategies are poorly understood by international students studying a marketing principles course at an Australian tertiary institution. Students find difficulties in conceptualising the various brand development strategies via purely written and verbal description even when many examples are given. Therefore alternative pedagogical strategies are required to enhance students' learning of particular concepts An empirical study, drawing upon cognitive psychology theory, was undertaken to determine whether an intervention strategy of using greater visual cues enhances international students' understanding and recall of the brand extension concept. The study was conducted with two business diploma classes undertaking a first year university marketing principles course. The intervention class was taught the concept with diagrams using relevant pictorial cues. The control class was taught the same concept with diagrams alone. Both groups were tested for understanding and recall of the concept after one week. Participant test results and survey questionnaires support the hypothesis that the addition of picture cues enhances students' comprehension as they mitigate the cognitive load caused by English vocabulary deficits. Picture cues prompted greater connections with students' prior knowledge increasing meaning construction and the verbal and visual encoding enabled elaborate processing resulting in higher recall of the concepts. Additionally participants' metacognitive reports proved the brand extension concept easier to recall when taught with imagery. These results indicate increased use of imagery can be a cost-effective strategy to enhance student learning when demonstrating new concepts to international students.
\end{abstract}

Key words: Concepts, comprehension, recall, imagery

Asian students studying abroad, in a second language, face a triple challenge: they must master the contents and concepts of their discipline, commonly through a language they do not fully command and often in educational environments that are culturally very different from their own (Watkins and Biggs, 1996). These challenges impact on comprehension and educators must recognise these obstacles and modify their practices to accommodate international students' unique learning needs. This paper proceeds to address these issues from a Cognitive Psychology and Educational Practice perspective.

The sensory memory perceives and processes incoming auditory and visual stimuli in restricted amounts at one time. Meaning is then constructed in the working memory by using students' prior knowledge, the context and their mental schemata (that act as abstractions from specific instances to help encode default assumptions and support storing and retrieval from long term memory).

\footnotetext{
*) This paper is based on 2012 research presented to the Athens International Conference on Business, July 1-4 2013, and the associated article submitted for inclusion in the 2013 ATINER CONFERENCE PAPER SERIES. Address all correspondence to C.Jane Edwards,e-mail: c.jane.edwards@unisa.edu.au
} 
Student's schemas also reduce pressure on the working memory by allowing multiple elements of information to be treated as a single chunk of category information (Anderson, 2010; Pressley, 1995). Yet due to the working memory's limited capacity, English as a second language (ESL), students often require extra processing because of their English vocabulary deficits. Working memory space can also become overloaded by anxiety when students do not fully comprehend academic language, resulting in less memory space available for processing of new information (Baddeley, 1986; Pressley, 1995; Watkins and Biggs, 1996).

Hummel and Nadolski (2002) explain that working memory load is also affected by the nature of the material, its presentation and the learner's effort. Thus educators should design their presentations to increase the germane cognitive load, whilst reducing extraneous load to aid comprehension by releasing working memory capacity to assist in the processing and encoding of new information and the propagating of schema. Therefore using tailored techniques to help students create new schemas should assist them to elaborate these ideas in other circumstances, as elaborative more meaningful processing evokes higher levels of activation and is effective because it is better at driving the brain processes that result in successful recall (Anderson, 2010).

According to Paivio's (1986) dual coding theory, information is represented in two distinct systems and these independent verbal and imaginal codes contribute additively to memory. Learners' differing cognitive abilities lead to individual learning preferences for auditory or visual stimuli and as visual and auditory information is processed separately in working memory, presenting information in both modalities can reduce the processing pressure on a single mode by spreading the cognitive load
(Baddeley, 1986; Mayer and Massa, 2003). Thus looking at picture diagrams can provide a visual scaffold that helps students construct the concept's meaning, which fits the likely visual preferences of international students (Mayer and Massa, 2003; Sternberg and Grigorenko, 2004).

Brain imaging studies show that the same regions are used in perception as in mental imagery and imagery enables humans to construct objects in their minds and inspect them - these images can later be scanned in search of critical information. Further research has found that it is more difficult to construct images from words alone and that memory for pictures is greater than verbal information (Anderson, 2010). However when explanations are also given whilst participants are studying pictures then better recall is achieved (Bower, Karlin and Dueck, 1975).

Studies also show the brain reacts to meaning and encodes what is important. Thus meaningful processing leads to better memory, with beneficial effects to both semantic and elaborative processing. Additionally, it is easier to commit arbitrary associations to memory if they are converted into something more meaningful and people tend to remember categorical information which gives them the ability to predict (Anderson, 2010). Thus, if international students are shown pictures in which they have prior knowledge and interest, the topic's meaning can compensate for their English language deficits to help activate their schemata and guide attention so information can be more easily assimilated to create new knowledge. Many studies have shown that organising and chunking related information in working memory is effective for increasing memory performance as the memory is not sensitive to the size of each chunk (Bruning, Schraw and Norby, 2011). Thus educators should aid students to chunk information on new concepts to enhance their encoding and recall. 
Matching teaching strategies to students' abilities maximises their strengths and minimises their weaknesses. Thus the use of visual cues can help ESL students become metacognitive to implement memory strategies that give them control over their processing and increase their motivation to learn (Sternberg and Grigorenko; 2004; Mayer and Massa 2003; Borkowski, Weyhing and Carr, 1988). All learning strategies should positively influence encoding practices with the goal to affect a learner's motivational state in the way they select, acquire, organise or integrate new information. Such metacognitive knowledge and use of strategies can compensate for lack of relevant prior knowledge and English vocabulary (Weinstein and Mayer 1986; Schraw, 1998; Zimmerman, 2002). This approach is relevant for international students of marketing and innovative teaching methods should be implemented to aid international students achieve the same degree of understanding as local students.

However observations from Chinese Diploma of Business students indicated that English proficiency and cultural background impacted on their comprehension of particular marketing concepts. Past exam results, from Eynesbury Institute of Business and Technology (EIBT) Adelaide, Australia revealed the brand extension concept was poorly understood and difficult to recall. Therefore a study using visual imagery strategy in regular classes was based primarily on working memory limitations according to cognitive load theory (Baddeley, 1986) and dual coding theory (Paivio, 1986) whilst incorporating motivational and metacognitive theories. Thus an intervention using visual imagery strategy embedded into regular class rooms, which included explicit cognitive and metacognitive instruction as recommended by Askel-Williams, Lawson and Skrzypiec (2012), was conducted.

\section{METHOD}

Hypothesis - The addition of relevant pictorial cues when teaching the concept of brand extension to ESL students will increase comprehension, encoding and recall and thereby improve test results.

\section{Sample}

To test the hypothesis, two randomly allocated classes, each of 35 Chinese Diploma of Business participants enrolled in a Marketing Principles Trading and Exchange course at EIBT were recruited for the experiment. The characteristics of both classes were similar in terms of ethnic origin, age (18-22 years), gender and English proficiency and the two groups were treated exactly alike in all ways except the differential treatment.

\section{Procedure}

The intervention was designed as a small, rapid module that easily fitted into the daily structure and process of the lecture. Participants were taught the brand extension concept and guided in practising different methods of encoding. In the following week the participants were given quiz questions to measure their concept understanding and recall followed by Likert scale questions to measure their metacognitive attitudes to the learning strategies.

The intervention group (Class 1) consisted of thirty five participants who were taught the concept of brand extension with pictorial/diagram cues. The control group (Class 2) consisted of thirty three participants who were taught the concept of brand extension with only diagram cues. Both classes were taught and tested on the concept by the same instructor to maintain internal validity. 
At the start of the class the instructor introduced the concept of Brand Strategies using PowerPoint slides from the Kotler, Brown, Burton, Deans \& Armstrong (2010) Marketing text (see Figure 11.8)

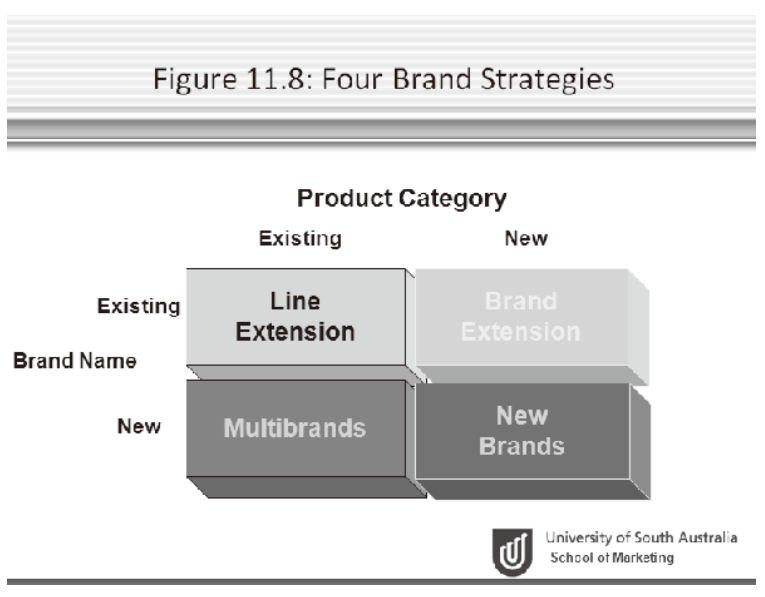

Line extension, multibrands and new brands were explained (in that order) with verbal_ examples. Brand extension (which occurs when a successful brand name launches a new product into a new product category) was then explained in detail for greater understanding. Additional inserted Intervention class or Control class PowerPoint (PP) slides were added to aid rehearsal and comprehension (see Fig 1 \& Fig 2).

Chanel (PP1) and Honda (PP2) brand extension examples were introduced to interest and motivate the 18-20 year old females and males respectively. These popular brands were chosen to assist meaning making as students' interest and prior knowledge would help them elaborate the information to aid encoding.

The instructor then elicited student elaboration and rehearsal of the concept by asking "Now who can think of any other brands such as airlines that have successfully extended their brands?" (It was expected that participants would link the brand extension concept to Virgin Airlines). Then the Virgin example (PP3) was displayed to increase the participants' self-efficacy for understanding the concept.

In both classes the Virgin Airlines slide remained on the screen for the instructor to then scaffold the participants to use cognitive and metacognitive strategies to help encode the brand extension concept (Askell-Williams et al. 2012; Wyra, Lawson and Hungi, 2007). Participants were supported to "Select" the brand extension information to be remembered; then "Relate" it to their prior knowledge; next to "Organise" the new information in memory by closing their eyes for 30 seconds to actively think about, visualise and encode the brand extension images and the meaning in their schemata; and finally to "Check" the concept was understood by asking for clarification if necessary.

Fig 1. Intervention class Power Point slides

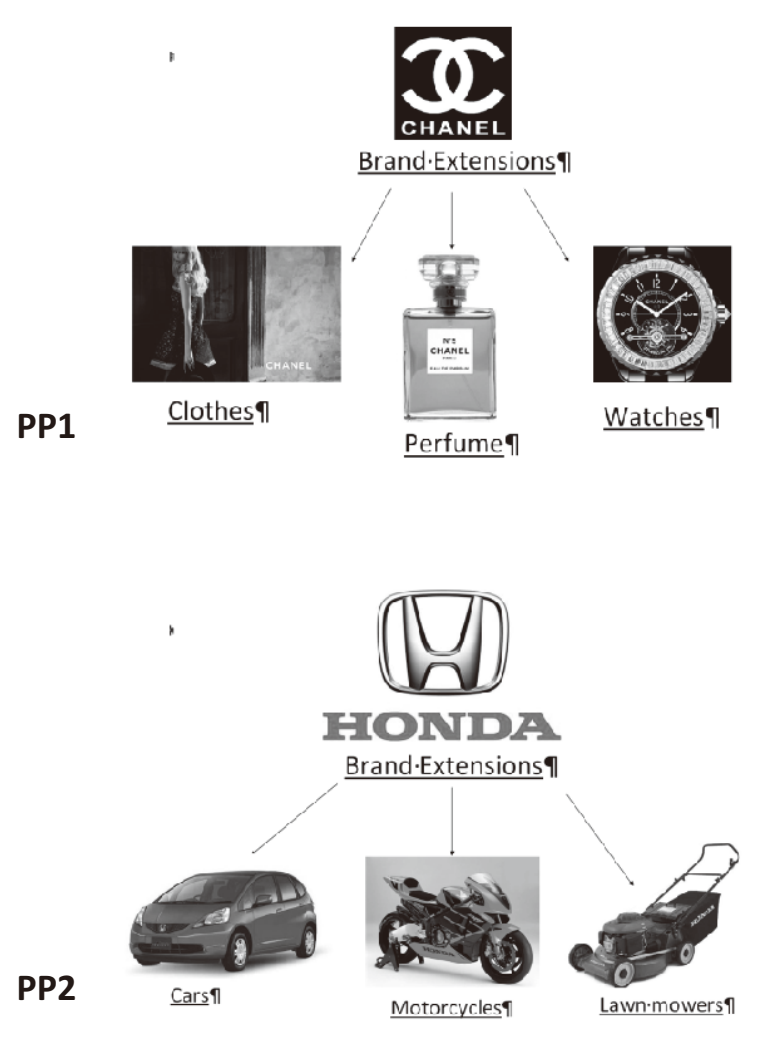




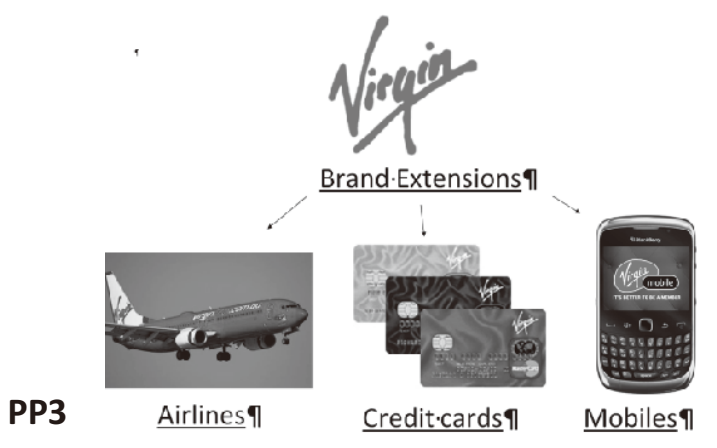

Fig 2. Control class Power Point slides

PP1

CHANEL

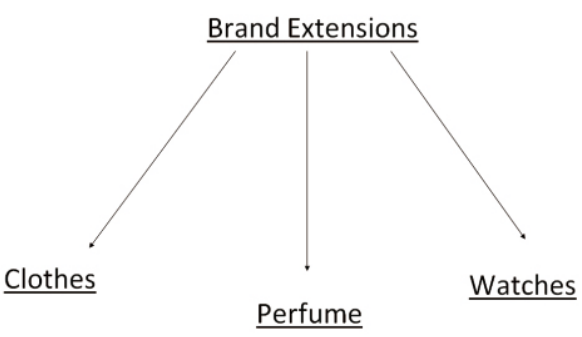

PP2

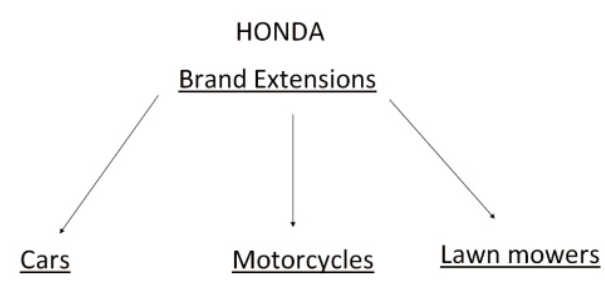

PP3

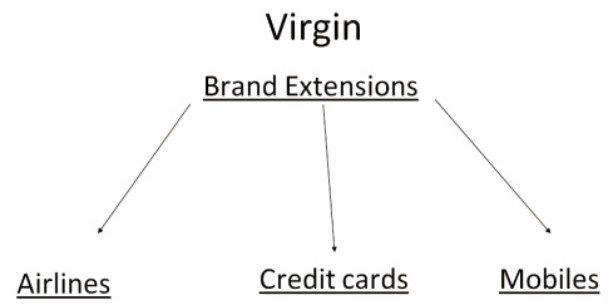

\section{Data collection}

There were two elements to measuring the interventions effectiveness. The first was the participants' quiz results, and the second was a Likert scale questionnaire. At the start of the following week's class participants were given quiz questions to measure their recall and understanding of the brand extension concept. This was part of a standard weekly quiz that forms a portion of the assessment. These questions were answered in writing on paper. After ten minutes the instructor collected all quiz answers.

Quiz Questions (and answer examples)

Q1 Explain what a Brand Extension means. (2 marks)

Q1a Typical 1mark answer $=$ A brand that uses the same (brand) name (1)

Q1b Typical 1 mark answer $=$ to launch a new product in a new product category (1)

Q2 Give an example. (1 mark)

Typical 1 mark examples $=$ Chanel sells clothes and perfume or Honda makes cars and motor bikes etc.

Q3 What does a brand need to launch a successful Brand Extension? (1 mark)

Typical 1 mark answer $=\underline{\text { strong positioning }}$ or highly regarded or trusted or has loyalty etc...

Q4 Name one advantage of a Brand Extension (1 mark)

Typical 1 mark answer = gain greater market share or helps companies enter new product categories easily or gives promotional efficiency or gives instant product recognition and product acceptance etc.

Question 1a and $1 \mathrm{~b}$ primarily tested the participants' recall of the brand extension concept whilst questions 2,3 and 4 tested the participants' understanding of the concept

Following the quiz the instructor distributed two paper based Likert scale questions to measure participants' attitudes to 
whether the diagrams and the cognitive strategies helped them remember the concepts. Below are the Likert scale questions.

\section{Intervention (Class 1)}

"Seeing the diagram with picture examples helped me remember what a Brand Extension means."

$$
\begin{array}{rr}
\text { Strongly } \\
\text { agree }
\end{array}
$$

"Thinking about a Brand Extension for thirty seconds helped me remember the concept more."

$$
\begin{array}{rrr}
\text { Strongly } & --1---2---3---4---5---6---7 & \begin{array}{l}
\text { Strongly } \\
\text { disagree }
\end{array}
\end{array}
$$

\section{Control (Class 2)}

"Seeing the diagram with examples helped me remember what a Brand Extension means."

$$
\begin{array}{r}
\text { Strongly } \\
\text { agree }
\end{array}
$$

"Thinking about a Brand Extension for thirty seconds helped me remember the concept more."

$$
\begin{array}{r}
\text { Strongly } \\
\text { agree }
\end{array}
$$

A quantitative analysis of the Quiz and Likert questionnaire results was performed using standard statistical tests (chi square and T-tests).

\section{DataAnalysis}

The two sets of quantitative data were collected, at the start of class, one week after the intervention. These consisted of results from both the quiz questions and the Likert scale questionnaire. The students' qualitative quiz answers were marked for recall and understanding of the brand extension concept, thus marks were awarded for meaning despite grammatical deficiencies. The quiz answers were independently checked by the second course lecturer to ensure accuracy and marking integrity.

\begin{tabular}{|c|c|c|c|c|c|c|}
\hline & $\begin{array}{l}\frac{\text { Same }}{\text { name }} \\
\underline{\text { Q1a }} \\
\frac{\text { Marks }}{(1)}\end{array}$ & $\begin{array}{l}\frac{\text { New }}{\text { category }} \\
\frac{\mathrm{Q} 1 \mathrm{~b}}{\text { Marks }} \\
\frac{(1)}{}\end{array}$ & $\begin{array}{l}\text { Example } \\
\frac{\mathrm{Q} 2}{\text { Marks }} \\
\frac{(1)}{}\end{array}$ & $\begin{array}{l}\frac{\text { Brand }}{\text { need }} \\
\frac{\mathrm{Q} 3}{\text { Marks }} \\
\frac{(1)}{\underline{1}}\end{array}$ & $\begin{array}{l}\text { Advantage } \\
\frac{\text { Q4 }}{\text { Marks }} \\
\underline{(1)}\end{array}$ & $\frac{\text { Overall }}{\frac{\text { Total }}{(5 \text { marks }}}$ \\
\hline $\begin{array}{c}\text { Intervention } \\
\text { Class 1 } \\
(\mathrm{N}=35) \\
\text { Total marks }\end{array}$ & 20 & 20 & 18.5 & 23 & 21.5 & 103 \\
\hline Mean & 0.57 & 0.57 & 0.53 & 0.66 & 0.61 & 2.94 \\
\hline $\begin{array}{c}\text { Control } \\
\text { Class } 2 \\
(\mathrm{~N}=25) \\
\text { Total marks }\end{array}$ & 9 & 7 & 5.5 & 8 & 11 & 40.5 \\
\hline Mean & 0.36 & 0.28 & 0.22 & 0.32 & 0.44 & 1.62 \\
\hline $\begin{array}{l}\text { Statistical } \\
\text { Significance }\end{array}$ & $\mathrm{P}<.05$ & $\mathbf{P}<.01$ & $P<.01$ & $\mathbf{P}<.01$ & $\mathbf{P}<.09$ & $\mathbf{P}<.003$ \\
\hline
\end{tabular}

\section{RESULTS}

\section{Results - Quiz}

Table 1. Quiz result

Table 1 details the overall total mean mark for Class 1 (intervention group) is 2.94 compared to the mean mark for Class 2 (control group) of 1.62. *This substantial variance is statistically significant at $99.9 \%$ using a one tailed (independent) t-test and demonstrates that the pictorial cues in the Class 1 intervention treatment had a significant positive effect on recall and understanding of the brand extension concept. *(using Microsoft EXCEL statistical package)

Additionally, the mean score for each question was higher for Class 1 than for Class 2. Question 1a and $1 \mathrm{~b}$ measured recall of the brand extension concept and the Class 1 mean for Q1a was 58\% higher than the Class 2 mean. The Class 1 Question $1 \mathrm{~b}$ score was $103 \%$ higher than Class 2's score. The scores on the recall questions then impacted on the Question 2, which tested understanding, by requiring an example of a brand extension. 
The Class 1 mean for Question 2 was 141\% higher than that of the Class 2 mean. This result seems logical because if students have difficulty in recalling the brand extension concept then providing an example of the concept is unlikely.

Class 1 means for the understanding questions 3 and 4 were $106 \%$ and $38 \%$ higher than the respective Class 2 means. These results remain statistically significant. The improved performance of Class 2 in these questions can be attributed to the broadness of these questions. As these questions were less specific than questions 1 and 2, general answers on business needs and advantages were rewarded with marks if they made sense.

There was some difference in the gender balance of the two classes; however analysis showed there was no statistical difference in mean results between male and female in both Classes 1 and 2. Hence the gender differences across classes had no impact in effecting overall performance scores.

In Class 1, thirty eight participants completed the quiz however the answers from the three participants who were absent for the previous week's intervention were discarded. In Class 2, although thirty three participants attended the research class in the prior week only 25 of these participants were present in the following week to undertake the quiz.

\section{Results - Likert Scale}

The Likert scale measures were used to determine participants' attitudes to the intervention learning strategies. Likert scale questions are routinely used in course evaluations at EIBT so the students were familiar with this type of attitude measurement. These paper based scales were distributed following the collection of the quiz results in both classes. To ensure true responses, these questionnaires were anonymous. In total only five students did not complete the Likert scale questions, which is a pleasing response as no marks were attached to their submission.

Table 2a: Likert results for Intervention group (Class 1) - question 1

\begin{tabular}{|c|c|c|c|c|c|c|c|c|}
\hline \multicolumn{9}{|c|}{$\begin{array}{l}\text { Seeing the diagram with picture examples helped me remember } \\
\text { what a Brand Extension means. }\end{array}$} \\
\hline $\begin{array}{l}\text { Strongly } \\
\text { agree }\end{array}$ & 1 & 2 & 3 & 4 & 5 & 6 & 7 & $\begin{array}{l}\text { Strongly } \\
\text { Disagree }\end{array}$ \\
\hline Frequency & 12 & 11 & 1 & 5 & 2 & 1 & 0 & \\
\hline$\%$ of total & $37.5 \%$ & $34.5 \%$ & $3.1 \%$ & $15.6 \%$ & $6.2 \%$ & 3. & & \\
\hline
\end{tabular}

Table 2b: Likert results for Intervention group (Class 1) - question 2

\begin{tabular}{|c|c|c|c|c|c|c|c|c|}
\hline \multicolumn{9}{|c|}{$\begin{array}{l}\text { Thinking about a Brand Extension for thirty seconds helped me } \\
\text { remember the concept more. }\end{array}$} \\
\hline $\begin{array}{l}\text { Strongly } \\
\text { agree }\end{array}$ & 1 & 2 & 3 & 4 & 5 & 6 & 7 & $\begin{array}{l}\text { Strongly } \\
\text { Disagree }\end{array}$ \\
\hline Frequency & 7 & 8 & 6 & 10 & 1 & 0 & 0 & \\
\hline$\%$ of total & $22 \%$ & $25 \%$ & $19 \%$ & $31 \%$ & $3 \%$ & 0 & 0 & \\
\hline
\end{tabular}


Table 3a: Likert results for Control group (Class 2) - question 1

\begin{tabular}{|c|c|c|c|c|c|c|c|c|}
\hline \multicolumn{9}{|c|}{$\begin{array}{l}\text { Seeing the diagram with examples helped me remember what } \\
\text { a Brand Extension means }\end{array}$} \\
\hline $\begin{array}{l}\text { Strongly } \\
\text { agree }\end{array}$ & 1 & 2 & 3 & 4 & 5 & 6 & 7 & $\begin{array}{l}\text { Strongly } \\
\text { Disagree }\end{array}$ \\
\hline Frequency & 0 & 5 & 11 & 6 & 2 & 1 & 0 & \\
\hline$\%$ of total & 0 & $21 \%$ & $44 \%$ & $24 \%$ & $8 \%$ & $4 \%$ & 0 & \\
\hline
\end{tabular}

Table 3b: Likert results for Control group (Class 2) - question 2

\begin{tabular}{|c|c|c|c|c|c|c|c|c|}
\hline \multicolumn{9}{|c|}{$\begin{array}{l}\text { Seeing the diagram with picture examples helped me remember } \\
\text { what a Brand Extension means. }\end{array}$} \\
\hline $\begin{array}{l}\text { Strongly } \\
\text { agree }\end{array}$ & 1 & 2 & 3 & 4 & 5 & 6 & 7 & $\begin{array}{l}\text { Strongly } \\
\text { Disagree }\end{array}$ \\
\hline Frequency & 12 & 11 & 1 & 5 & 2 & 1 & 0 & \\
\hline$\%$ of total & $37.5 \%$ & $34.5 \%$ & $3.1 \%$ & $15.6 \%$ & $6.2 \%$ & & & \\
\hline
\end{tabular}

These Likert scale results demonstrate strong differences in students' attitudes between Class 1 and Class 2 regarding the value the diagrams had in helping them to remember the brand extension concept. Similarly, Class 1 and Class 2 varied in the value of the two different diagrams for metacognitively making images to help them remember the concept.

From Table $2 \mathrm{a}$, for Class $1,72 \%$ of the participants responded Strongly Agree/Agree that the diagram with picture examples helped them remember the brand extension concept. In contrast, for Class 2, (Table $3 b$ ) only $21 \%$ agreed that the diagram with word examples helped them remember what the brand extension concept meant. Clearly the diagram with picture examples aided students to encode and recall the concept more than the diagram with word examples only.

Similarly, Table $2 \mathrm{~b}$ reveals that for Class 1 (responding to question 2) $47 \%$ Strongly Agree/Agree that the 30 seconds of thinking about the brand extension concept helped them whilst the remainder of the participants $(53 \%)$ were unsure of this activities worth as their responses were between 3 and 5 . However in contrast, Class 2 participants were largely unsure of the activities value as $83 \%$ chose from 3 to 5 on the scale, with only $17 \%$ of students responding Agree.

Overall, Class 1 reported the diagram with picture examples much more useful in helping them remember the brand extension concept than did Class 2 who viewed the diagram without pictures.

Chi-square tests reveal that the frequency distribution between Class 1 and Class 2 for questions 1 and 2 were statistically different (at 99\% and 95\% respectively). In addition when combining the two questions, the differences in frequency distribution between the two classes were statistically significant at $99 \%(\mathrm{p}<.001)$.

\section{DISCUSSION}

The results of this study strongly support the hypothesis that the use of visual cues aid understanding, encoding and recall for ESL business diploma students. Importantly this offers a successful teaching strategy that compensates for students English language deficits by using an embedded visual support device that assists meaning construction and helps students to comply 
with the task (Hummel and Nadolski, 2002). The research design also included motivational aspects to interest students to gain attention and perception. The use of meaningful examples such as Chanel, Honda and Virgin aimed at interesting both females and males were effective and resulted in improved memory in line with previous research that demonstrated that interesting and meaningful processing aids memory (Anderson, 2010).

The pictorial cues also increased the students' understanding of the concept by utilising their limited working memory capacity for meaning construction of the germane load rather than using valuable memory capacity in understanding the complex English explanations (Mayer and Massa, 2003). These findings concur with cognitive load theory as the results indicate the picture examples used less working memory space for word decoding thus releasing working memory capacity to be involved in encoding the new information (Baddeley, 1986; Mayer and Massa, 2003). These pictorial cues optimised the use of the students' working memories so that they could both process information and propagate schemata construction at the same time (Hummel and Nadolski, 2002; Baddeley, 1986).

The results also reinforce work by Paivio (1986) whose dual coding theory states that individuals represent information in verbal and imaginal systems and that these two independent codes contribute individually and additively to memory. The Class 1 students who were shown pictorial diagram cues of brand extensions showed almost double the concept recall of Class 2 students who saw the diagrams with words alone, indicating that the addition of picture cues evoked stronger memories. These results also replicate research showing explanations coupled with pictures give better recall and that it is difficult for subjects to construct images from words alone (Bower, Karlin and Dweck, 1975; Franklin and Tversky, 1990).

Students in Class 1 performed better in all measurement categories due to a combination of the previously discussed cognitive influences. The picture examples decreased the extrinsic cognitive load, caused by the concept's English language complexity, to help them to understand the meaning of a brand extension. The students' prior knowledge of the brands and the richness of the picture cues enabled them to activate their schemata and incorporate the new information. The visual images meaning was coded as a chunk of category information in their schemata, aided by their prior knowledge and interest in the brands. This information chunk could later act like a mnemonic, where a student could recall that Chanel, Honda or Virgin made different categories of products and this concept was linked with the term brand extension, where a brand name extends to different product categories.

In the following week's quiz, students activated their schemata to scan the brand extension image and reconstruct the memory that Chanel made clothes, perfume and watches. Thus they were able to recall that a brand extension meant different product categories made under the same brand name. This reconstructive cognitive process was less available for Class 2 as demonstrated by the vast difference in results.

The results of Question 2 showed a pleasing amount of elaboration of the concept however again Class 1 outperformed Class 2 by $141 \%$. Although students used the examples given in the intervention many students also used their prior knowledge, activated their schemata and elaborated on the concept by giving interesting brand extension examples such as Samsung, Apple and Google. These examples are indications of students' elaborations where they have made 
external connections to prior knowledge to generate examples of the Brand Extension concept (Weinstein and Mayer, 1986). In contrast Class 2, who only saw the word diagrams, were less able to create images in their minds and so less able to scan an image for information on the brand extension concept.

Question 3 results were very pleasing for Class 1, as this was the highest overall score with $66 \%$ of students answering the question correctly. This question measured understanding of the concept and the class gave very strong answers such as "loyalty, reputation, famous, influence" that showed they understood the requirements for a brand to launch successful brand extensions. In comparison Class 2 were unable to articulate this understanding and scored less than half the marks of Class 1 . It is believed that the picture cues instilled stronger images in Class 1 students' minds enabling them to scan their images and see Chanel and Honda and Virgin examples and reason that they are famous and reputable to a greater extent than Class 2 where the word cues were not as easy to image (Franklin and Traversky, 1990).

The wording of Question 4 which asked for advantages of brand extensions could have been more specifically related to brand extensions as many students gave general business answers such as increase sales, expand market, and attract consumers and the like. Whilst technically these can also be advantages of brand extensions, the quiz was seeking answers more specific to brand extensions however all meaningful answers were awarded marks. This may explain why question 4 was the highest mean for Class 2 . Because Class 2 were unable to recall or understand the brand extension concept well they had to rely on gaining marks with generic business answers.

The inclusion of the Likert scale questions served two purposes. Firstly they required students to think metacognitively about their learning and memory and secondly they measured their attitudes to the learning strategies (Zimmerman, 2002). Consistent with the study's hypothesis, students in Class 1 demonstrated they believed the picture diagrams helped them remember the brand extension concept to a far greater extent than Class 2.

It is anticipated this exercise will inspire students to become more metacognitive by understanding their strengths and weaknesses to seek out visual cues and spend effort in imaging those cues to aid their memory for new information (Baddeley (1986); Paivio (1986); Mayer and Massa 2003; Sternberg and Grigorenko, 2004).

\section{CONCLUSION}

With the current educational demand for improved learning outcomes combined with fiscal constraints, using pictorial cues to aid cognition is a cost effective method of teaching new concepts. While this research was conducted on international diploma of business students it is believed the results have external validity for educators of other disciplines and students regardless of their language. With the rapidly changing technological environment students are utilising increasing visual and pictorial means to interact with information. It is the role of educators to adapt their teaching strategies to benefit the needs of their students. Increasing pictorial cues to aid encoding and recall is an opportunity that should be fully exploited. This research has proved successful and prompts further studies in the area. 


\section{DAFTAR PUSTAKA}

Anderson, J.R. (2010). Cognitive Psychology and Its Implications $\left(7^{\text {th }}\right.$ edition). New York: Worth.

Askell-Williams, H., Lawson, M.J., \& Skrzypiec, G. (2012). Scaffolding cognitive and metacognitive strategy instruction in regular class lessons. Instructional Science, 40,413-443.

Baddeley, A.D. (1986). Working memory. Oxford: Oxford University Press.

Borkowski, J. G., Wehing, R. S., \& Carr, M. (1988). Effects of attributional retraining on strategy-based reading comprehension in learning-disabled students. Journal of Educational Psychology, 80, 46-53.

Bower, G.H., Karlin, M.B., \& Dueck, A. (1975). Comprehension and memory for pictures. Memory \& Cognition, 3, 216-220.

Bruning, R.H., Schraw, G.J., \& Norby, M.N. (2011). Cognitive Psychology and Instruction $\left(5^{\text {th }}\right.$ edition). Upper Saddle River, NJ: Pearson.

Franklin, N., \& Tversky, B. (1990). Searching imagined environments. Journal of Experimental Psychology, General. 119, 63-76.

Hummel, H. G. K., \& Nadolski R.J. (2002). Cueing for schema construction: designing problem-solving multimedia practicals. Contemporary Educational Psychology, 27, 229-249.

Kotler, P., Brown, L., Burton, S., Deans, K., \& Armstrong, G. (2010). Marketing (8th edition). Frenchs Forest: Pearson Australia.

Mayer, R. E., \& Massa, L. J. (2003). Three facets of visual and verbal learners: Cognitive ability, cognitive style, and learning preference. Journal of Educational Psychology, 95(4), 833-846.
Paivio, A. (1986). Mental representations: A dual coding approach. New York: Oxford University Press.

Pressley, M. (1995). Introduction: good thinking, good teaching, and alternative ways of studying good thinking and good teaching. In M. Pressley \& C. McCormick (Eds.), Cognition, teaching, and assessment (pp. 124). New York: Harper Collins College Publishers.

Schraw, G. (1998). Promoting general metacognitive awareness. Instructional Science, 26, 113-125.

Sternberg, R. J., \& Grigorenko, E.L. (2004). Successful intelligence in the classroom. Theory into Practice, 43, 274-280.

Watkins, D.A., \& Biggs, J.B. (Eds.). (1996). The Chinese Learner: Cultural, Psychological, and Contextual Influences. Camberwell Melbourne Victoria: Comparative, Education Research Centre Hong Kong and The Australian Council for Educational Research Ltd.

Wyra, M., Lawson, M.J., \& Hungi, N. (2007). The mnemonic keyword method: The effects of bidirectional retrieval training and the ability to image on foreign language vocabulary recall. Learning and Instruction, 17, 360-371.

Zimmerman, B. J. (2002). Becoming a selfregulated learner. Theory into Practice, 41, 64-70. 